\title{
Adherence to Therapies in Patients with Type 2 Diabetes
}

Luis-Emilio García-Pérez • María Álvarez • Tatiana Dilla •

Vicente Gil-Guillén • Domingo Orozco-Beltrán

To view enhanced content go to www.diabetestherapy-open.com

Received: June 5, 2013 / Published online: August 30, 2013

(C) The Author(s) 2013. This article is published with open access at Springerlink.com

\section{ABSTRACT}

Adherence to therapy is defined as the extent to which a person's behavior in taking medication, following a diet, and/or executing lifestyle changes, corresponds with agreed recommendations from a healthcare provider. Patients presenting with type 2 diabetes mellitus are initially encouraged to maintain a healthy diet and exercise regimen, followed by early medication that generally includes one or more oral hypoglycemic agents and later may

\section{L.-E. García-Pérez ( $\square)$}

Global Medical Affairs, Medical Department, Lilly, S.A., Avda. de la Industria 30, 28108 Alcobendas, Madrid, Spain

e-mail: garcia_luis-emilio@lilly.com

M. Álvarez · T. Dilla

Medical Department, Lilly, S.A., Alcobendas, Madrid, Spain

V. Gil-Guillén · D. Orozco-Beltrán Department of Clinical Medicine, Cathedra of Family Medicine, University Miguel Hernández, Alicante, Spain

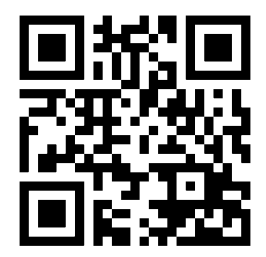

Enhanced content for this article is available on the journal web site: www.diabetestherapy-open.com include an injectable treatment. To prevent the complications associated with type 2 diabetes, therapy frequently also includes medications for control of blood pressure, dyslipidemia and other disorders, since patients often have more than three or four chronic conditions. Despite the benefits of therapy, studies have indicated that recommended glycemic goals are achieved by less than $50 \%$ of patients, which may be associated with decreased adherence to therapies. As a result, hyperglycemia and longterm complications increase morbidity and premature mortality, and lead to increased costs to health services. Reasons for nonadherence are multifactorial and difficult to identify. They include age, information, perception and duration of disease, complexity of dosing regimen, polytherapy, psychological factors, safety, tolerability and cost. Various measures to increase patient satisfaction and increase adherence in type 2 diabetes have been investigated. These include reducing the complexity of therapy by fixed-dose combination pills and less frequent dosing regimens, using medications that are associated with fewer adverse events (hypoglycemia or weight gain), educational 
initiatives with improved patient-healthcare provider communication, reminder systems and social support to help reduce costs. In the current narrative review, factors that influence adherence to different therapies for type 2 diabetes are discussed, along with outcomes of poor adherence, the economic impact of nonadherence, and strategies aimed at improving adherence.

Keywords: Adherence; Dosing complexity; Glycemic control; Primary care; Type 2 diabetes

\section{INTRODUCTION}

The prevalence of type 2 diabetes mellitus is increasing globally and has become a major public health problem. In the USA, a study of 17,306 people over 20 years of age showed that those diagnosed with diabetes increased significantly from $6.5 \%$ in the 1999-2002 period to $7.8 \%$ in 2003-2006 [1]. In 2011, 366 million people worldwide had diabetes and it is predicted that by 2030, this figure will be 552 million [2]. Diabetes is currently among the top five causes of death in most high-income countries and resulted in 4.6 million deaths globally in 2011. The majority of cases of diabetes mellitus are type 2 , and the greatest numbers of people with this disease are aged from 40 to 59 years [2].

The increase in type 2 diabetes is associated with obesity, hypertension, and an increasingly elderly population. Over the last 18 years in the USA, the proportion of adults in the age group $40-74$ years with a body mass index $\geq 30 \mathrm{~kg} / \mathrm{m}^{2}$ has increased from $28 \%$ to $36 \%$, while the proportion undergoing physical activity 12 times a month or more has decreased from $53 \%$ to $43 \%$, exacerbating the obesity problem [3]. However, despite strong clinical recommendations for individuals with a history of diabetes to adopt a healthier lifestyle, adherence to improved diet and exercise is poor [3]. Although type 2 diabetes usually occurs in people over the age of 40 years, it is becoming increasingly common in children, adolescents and young adults due to reduced physical activity and unhealthy eating patterns, leading to obesity [4].

The majority of patients with type 2 diabetes fail to control glycemia with diet and exercise and require pharmacotherapy-in general, initially monotherapy with an oral hypoglycemic agents (OHA); however, owing to the progressive nature of the disease, most of the patients will eventually require combination therapy and ultimately injectable treatments as monotherapy or part of polytherapy. Glycemic control in type 2 diabetes is essential to prevent long-term micro- and macrovascular complications [5]. A number of factors other than glycated hemoglobin $\left(\mathrm{HbA}_{1 \mathrm{c}}\right)$ level will influence treatment regimens, and practice guidelines emphasize the need for concomitant treatment of other cardiovascular risk factors, such as arterial hypertension ( $\geq 140 / 80 \mathrm{mmHg}$ ) and dyslipidemia [low density lipoprotein (LDL) $>2.6 \mathrm{mmol} / \mathrm{L}$; triglycerides $>1.7 \mathrm{mmol} / \mathrm{L}$ ] [5]. As a consequence, many patients with type 2 diabetes are taking a complex regimen of drugs [6].

Drugs and lifestyle changes to control type 2 diabetes and associated conditions can only be effective through adherence to the overall prescribed regimen. The World Health Organization (WHO) has shown that adherence to long-term therapy for chronic illnesses in developed countries averages only around 50\% [7]. Adherence rates are usually reduced for patients with chronic conditions than those with acute conditions; this is 
associated with the long-term nature of chronic diseases because the decline in adherence is most rapid after the first 6 months of therapy [8]. Such reduced adherence not only results in poor health outcomes but it also has a significant impact on healthcare costs [7]. Thus, the overall management of type 2 diabetes should address adherence as well as appropriate medications.

\section{MATERIALS AND METHODS}

The current narrative review examined factors that influence adherence to various therapies for type 2 diabetes, the outcomes of poor adherence, the economic impact of nonadherence, and strategies designed to improve adherence. A literature search using PubMed was performed using the key terms of "type 2 diabetes", and "adherence" or "compliance" or "persistence". The search included publications regarding clinical trials, and epidemiology and evidence reviews, in English or Spanish, with no restriction on dates.

\section{Definitions}

Adherence, compliance and persistence are terms used to define the extent to which a patient conforms to the prescribed medication, and are factors that have a major impact on the outcomes of treatment. Although there has been a lack of uniformity in definitions describing the use of prescribed drugs, some attempts have been made to clearly define these terms [7-9].

\section{Adherence and Compliance}

Adherence, as used in chronic disorders, was defined by the WHO as the extent to which a person's behavior with respect to taking medication, following a diet, and/or executing lifestyle changes, corresponds with agreed recommendations from a healthcare provider
[7]. Methods of measuring adherence can be either direct (biological marker), which is more sensitive but can be invasive and is not usually practical, or indirect (self-reporting, questionnaires, pill counts) [10]. Indirect methods are frequently used, but can lead to inaccuracies since patients are often not a reliable source of information. Electronic pharmacy data are now readily available and more recently this indirect method has been widely used to assess adherence. There are two common measures of adherence using such data: the medication possession ratio (MPR; days of medication collected as a proportion of days of medication prescribed over a particular period) and the proportion of days covered within a given time period. These measures correlate with the quantity of doses prescribed, but not their actual administration or timing [11]. Adherence is usually regarded as the proportion of patients taking at least $80 \%$ of their prescribed medication [12], but this cut-off can be up to $90 \%$ in some studies [13]. In general, most studies have measured adherence in patients continuing medication, which may underestimate the health burden of poor adherence for the newly prescribed drugs. Electronic medical records have facilitated more comprehensive assessments of patients prescribed medication and should increase the reliability of studies on first-time users (primary) and improve data on continuing medication (secondary) [14].

Compliance is a term that is often used synonymously with adherence and is usually measured as the administered doses as a proportion of the prescribed doses over a period of time $[15,16]$. While it differs slightly from adherence in that it does not require the patient's agreement to the recommendations [7], the terminology used in the present report is consistent with the quoted reference. 


\section{Persistence}

The outcomes of treatment are affected not only by conformity with day-to-day treatment, but also by the length of time treatment is continued during the prescribed duration. Treatment persistence is usually defined as the duration of time that a patient continues treatment as a proportion of the prescribed duration [9]. It is measured as either the proportion of patients who remain on treatment for a specified period or the mean number of days to treatment discontinuation.

\section{ADHERENCE TO RECOMMENDED THERAPIES}

Despite the extensive therapy options available for various stages of type 2 diabetes, studies have indicated that less than $50 \%$ of patients achieve the glycemic goals recommended by the American Diabetes Association (ADA) and approximately two-thirds die prematurely of cardiovascular disease [17]. Although data from a study in the USA indicated an increase in the percentage of people with diagnosed diabetes who achieved glycemic, cardiovascular and lipid control from $7.0 \%$ to $12.2 \%$ during the period 1999 to 2006, adherence was still very low, with considerable room for improvement [1].

\section{Diet and Exercise}

Guidelines from the ADA and the European Association for the Study of Diabetes (EASD) stress the importance of diet and exercise in the treatment of all stages of type 2 diabetes [18]. Despite evidence for the benefits of exercise, adherence to long-term exercise programs can vary between $10 \%$ and $80 \%$, particularly in the long term [19]. There is evidence that patients often have numerous cycles of weight loss and relapse before managing to maintain their weight loss, suggesting that healthcare professionals should consistently encourage therapeutic lifestyle changes $[5,18]$. The factors that influence adherence to exercise include overuse injuries and lack of motivation [20], and whether the activity is routinely monitored [21]. However, in a survey of attitudes to adherence to diet and exercise, patients with type 2 diabetes and their diabetes educators viewed barriers differently [22]. With regard to diet, patients expressed a dislike for foods included in meal plans, whereas the educators considered social influences as more important barriers. With respect to exercise, diabetes educators considered a lack of motivation and physical problems to be the prominent barriers to adherence, whereas patients reported barriers to be largely related to convenience, including factors such as the weather; however, only about one-quarter of the patients reported that they had been provided with an exercise plan [22].

\section{Oral Hypoglycemic Agents}

There are numerous reviews indicating the lack of adherence to treatment with one or more OHAs. It has been demonstrated that there is an inverse relationship between taking a prescribed $\mathrm{OHA}$ and $\mathrm{HbA}_{1 \mathrm{c}}$ level, with each $10 \%$ increase in OHA adherence associated with a decrease of $0.1 \%$ in $\mathrm{HbA}_{1 \mathrm{c}}(P<0.001)$ [23]. Nevertheless, in an analysis of 11 retrospective studies between 1966 and 2003, adherence (defined in some of the studies as taking $90 \%$ of medication) to OHA therapy ranged from $36 \%$ to $93 \%$ in patients remaining on treatment for 6-24 months [24]. Prospective analyses of adherence using electronic 
monitoring indicated that patients took $61-85 \%$ of OHA doses as prescribed. In an extensive study of electronic records for various medications in patients with diabetes, among 8,191 patients prescribed glucoselowering therapies, only $39.6 \%$ were persistent after 24 months and $4.0 \%$ never filled their prescription (primary nonadherence), despite $53 \%$ having $\mathrm{HbA}_{1 \mathrm{c}}$ $\geq 7 \%$ [14]. Using self-reported compliance, a prospective assessment of 11,896 patients treated with one or two OHAs found that only $46 \%$ of cases demonstrated optimal compliance [25]. In a more recent retrospective analysis of the health records of 2,741 patients with type 2 diabetes who had recently initiated OHA therapy, overall adherence was $81 \%$, with $65 \%$ of patients having good adherence $(\geq 80 \%$ of medication) [23].

These variations in estimates of adherence between studies are due to a number of factors, including methodology for measurement of adherence, patient populations (socioeconomic effects) and differences in the cut-off point used for defining adherence. Data for the majority of these surveys included only secondary adherence and hence, the problem is likely to be greater than indicated if primary nonadherence was included. In a longitudinal retrospective cohort study that evaluated early nonadherence in new-user cohorts using electronic medical record data from 1992 to 2001, 90\% of patients filled their first prescription for metformin or sulfonylurea within 30 days [26]. However, there were high rates of early discontinuation and, after 6 months, only $73 \%$ of patients continued therapy.

\section{Insulin}

As diabetes progresses, insulin may be initiated alone or in addition to an OHA; patients may also be taking therapy for associated complications. In retrospective insulin studies, adherence was $62 \%$ and $64 \%$ for long-term and new-start insulin users, respectively [24]. In insulin-naïve patients who were prescribed insulin, primary nonadherence, assessed from unfilled prescriptions, was reported for $4.5 \%$ of patients, and an additional $25.5 \%$ of patients never obtained a refill [14, 27].

According to a study of 1,099 patients with type 2 diabetes who were treated with insulin in Scotland between 1995 and 2001, the average adherence to insulin treatment (measured as the percentage of the number of days per annum of insulin coverage) was $71 \%$ (Fig. 1) [28]. The level of adherence was a significant predictor of $\mathrm{HbA}_{1 \mathrm{c}}$, indicating that improved adherence resulted in better glycemic control. In a Spanish study of 294 patients with type 2 diabetes, patients self-assessed their level of compliance using a questionnaire [29]. The highest compliance was seen in patients taking only insulin (67\%; Table 1), whereas the lowest compliance was in patients taking insulin plus an OHA (39\%). Surprisingly, for patients taking only OHAs, the compliance level was similar for monotherapy and combination therapies.

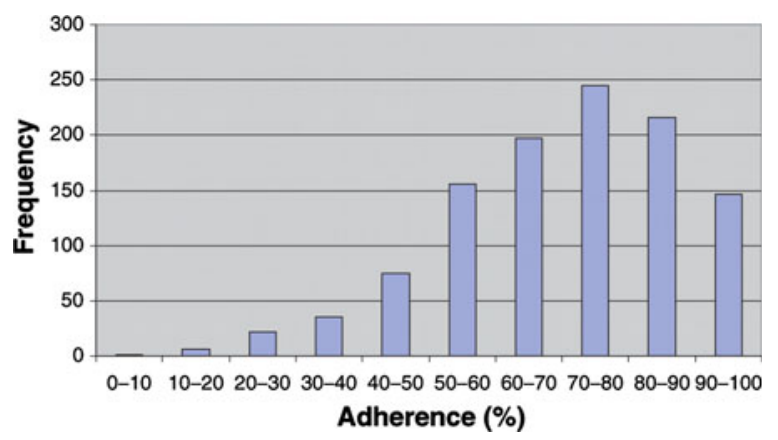

Fig. 1 Number of patients adhering to insulin therapy (frequency) versus percent of the number of days of drug adherence per annum for 1,099 patients with type 2 diabetes mellitus in Scotland; reproduced with permission from Donnelly et al. [28] 
Table 1 Percent of patients with reported level of treatment adherence by type of pharmacologic treatment; reproduced with permission from Yurgin et al. [29]

\begin{tabular}{|c|c|c|c|c|c|c|}
\hline & \multirow[t]{2}{*}{ All treatments } & \multicolumn{2}{|l|}{ Oral therapy } & \multicolumn{3}{|c|}{ Insulin therapy } \\
\hline & & Monotherapy & Combination & Monotherapy & Combination & $\overline{\text { Plus OHA }}$ \\
\hline High compliance & 50 & 49 & 50 & 67 & 57 & 39 \\
\hline Moderate compliance & 41 & 41 & 42 & 29 & 29 & 47 \\
\hline Low compliance & 9 & 10 & 8 & 4 & 14 & 14 \\
\hline
\end{tabular}

$O H A$ oral hypoglycemic agent

\section{Antihypertensives and Lipid-Lowering Therapies}

Although a beneficial effect of glycemic control on microvascular and macrovascular complications has been observed, patients with type 2 diabetes generally still have an increased risk for cardiovascular complications. A meta-analysis of five prospective, randomized, controlled trials investigating intensive control of glucose in 33,040 participants with type 2 diabetes showed that $4.5 \%$ had non-fatal myocardial infarction, $7.0 \%$ had coronary heart disease, $3.4 \%$ had stroke and $8.8 \%$ had all-cause mortality during approximately 163,000 person-years of follow-up [30]. Nonfatal myocardial infarction and events associated with coronary heart disease can be reduced with intensive glucose-lowering treatment, but this involves more medications than conventional treatment [30]. To counteract the complications associated with type 2 diabetes, therapy frequently includes medications for the control of blood pressure and lipid metabolism. Analysis of data from 840 patients showed that 629 (75\%) had high adherence to antihypertensive monotherapy and these patients were $45 \%$ more likely to achieve blood pressure control than those with medium or low compliance [31]. Adherence to statin therapy to control lipids in 6,462 patients with diabetes was also reported to be poor, with a decrease from $87 \%$ in the first 3 months to less than 50\% from 6 months onwards [32]. Poor adherence was significantly correlated with the occurrence of subsequent coronary heart disease and stroke.

Electronic data from a study from January to June 2006 showed that $22.3 \%$ of 27,329 patients with diabetes did not become ongoing users of prescribed cardiometabolic therapies, a further $6.4 \%$ discontinued therapy and only $39 \%$ of the patients were persistent users at 24 months [14]. Only $33.2 \%$ of 6,426 patients prescribed a lipid-lowering therapy and $41.5 \%$ of patients prescribed an antihypertensive persisted with therapy at 24 months. Secondary assessments in the study showed that $28.9 \%$ of patients had poor adherence. When patients who were prescribed a new medication were assessed (primary adherence), $47.4 \%$ were found to have poor adherence levels.

\section{FACTORS INFLUENCING ADHERENCE}

There are many potential reasons for nonadherence to medication and, frequently, more than one is present for any given patient. The reasons for medication adherence are multifactorial and difficult to identify; they include age, perception and duration of 
disease, polytherapy, psychological factors, safety, tolerability, and cost. Some of these factors cannot be altered, although others are amenable to modification.

\section{Complexity of Dosing Regimens}

The chronic progressive nature of type 2 diabetes means that once started, patients will not only take medication for life, but the complexity of the medication regimen is likely to increase over time. Over the last two decades, as understanding of the disease has increased steadily, there has been an increased complexity in the therapy administered. According to an assessment carried out in the USA, where the number of prescriptions issued between 1991 and 2000 was measured, the number of patients who had at least five prescriptions increased from $18.2 \%$ to $29.9 \%(P<0.001)$ [6]. Indeed, multifactorial medication for diabetes and related complications can involve up to 10 tablets per day [33], and there is no doubt that the complexity of treatments has a profound influence on adherence [34]. For example, in a study of patients starting bisphosphonates for osteoporosis, an increasing burden of comorbidities, including diabetes, was shown to be associated with decreased compliance with medications [35].

In general, patients with type 2 diabetes begin pharmacotherapy with metformin, but progress to more than one prescribed OHA to maintain glycemic control $[5,18]$. There have been a number of studies of compliance with OHAs and the majority indicate that adherence declines as the number of drugs increases [36]. Because type 2 diabetes is progressive, and oral therapies fail to control $\mathrm{HbA}_{1 \mathrm{c}}$ over time, most patients will eventually resort to injectable regimens and adherence to these is low [37].

\section{Safety and Tolerability}

Nonadherence could also be due to adverse events associated with medications. The majority of patients with type 2 diabetes are overweight or obese at diagnosis, and some of the current therapeutic options are associated with weight gain and hypoglycemia. In a retrospective study of 294 patients, obese or severely obese patients were 2.2 times more likely to have low or moderate compliance compared with non-obese patients [95\% confidence interval (CI) 1.31-3.74; $P=0.002$ ] [38]. From a meta-analysis of five studies, it was concluded that intensive treatment of type 2 diabetes, where targets for $\mathrm{HbA}_{1 \mathrm{c}}$ are lower, can significantly reduce $\mathrm{HbA}_{1 \mathrm{c}}$ level compared with conventional treatment, and may be associated with a reduction of cardiovascular events and myocardial infarction [39]. However, recent results from large clinical trials have indicated that intensive glucose control does not reduce macrovascular disease in older patients with long-standing diabetes [40] and may be associated with increased mortality [41]. Intensive treatment has also resulted in a higher body mass index and an increased incidence of severe hypoglycemia [39, 41]. Medication-related weight gain and increased cardiovascular risk associated with intensive treatment are significant predictors of medication nonadherence [42].

Other less serious side effects, such as gastrointestinal problems, may also affect adherence. Extended-release metformin was associated with significantly less gastrointestinal events than immediate-release metformin, and adherence was significantly greater in patients who used the extendedrelease formulation than in those who took the immediate-release medication [43]. 
It is important to take into account such tolerability issues when considering long-term therapy. In a survey of data from 2,074 patients with type 2 diabetes taking more than one OHA, but not insulin, between 2006 and 2008 in the USA, the majority (71.7\%) had experienced at least one tolerability issue (hypoglycemia, constipation/diarrhea, headaches, weight gain and water retention) in the prior 2 weeks and $49.7 \%$ had experienced more than two issues [44]. The association between the number of tolerability issues and the likelihood of nonadherence was significant $(r=0.20, \quad P<0.01)$ and each additional tolerability issue was associated with $28 \%$ greater probability of nonadherence.

\section{Perceptions of Medication}

The perception of efficacy in terms of treatment can also have a significant effect on adherence. In a study of 49 patients with type 1 and 108 patients with type 2 diabetes, perceptions of glycemic control and prevention of cardiovascular complications were associated with adherence to insulin, lipid-lowering and antihypertensive medications, as well as exercise and diet [45]. The authors concluded that patients hold specific mental models about diabetes treatments, which are associated with adherence. In a study of statin treatment in patients with diabetes, adherence was worst in those who considered themselves at lowest risk for cardiovascular disease at the start [32]. An exploratory survey among 121 patients with type 2 diabetes showed that $32.8 \%$ thought medication would cause unpleasant side effects and $13.9 \%$ thought it would lead to weight gain, and these factors were associated with reduced medication adherence [46].

There is considerable resistance among patients to the initiation of injection regimens.
In the Diabetes Attitudes, Wishes and Needs (DAWN) study, $48 \%$ of insulin-naïve patients with type 2 diabetes perceived insulin initiation as a failure to adequately manage their disease [47]. Efficacy of insulin was perceived to be low and only about one-fifth of the patients and one-half of the physicians believed that insulin would improve management of the diabetes. Psychological insulin resistance was seen in another study of insulin-naïve patients [48]. Patients unwilling to accept insulin reported an objection to lifelong insulin use and, compared with patients willing to accept insulin, were more likely to see its use as due to their failure to control the disease. In patients newly prescribed with insulin, $35 \%$ who were nonadherent believed that insulin caused harm and frequently felt that the risks and benefits of insulin had not been adequately explained [27]. The most common reasons given for failing to initiate insulin were plans to change health behavior (25\%), injection phobia (13\%), negative impact on work (9\%), concerns about long-term medication use (9\%), inconvenience $(6 \%)$, and not believing insulin was necessary (6\%). In a prospective self-report survey of 100 adult insulin-naïve patients with type 2 diabetes, 33\% were unwilling to take insulin due to concerns regarding hypoglycemia, the permanent need for insulin therapy, less flexibility and feelings of failure [49].

\section{Economic Considerations}

In lower-income groups, the cost of medications can be a reason for a lack of adherence. A cross-sectional analysis of baseline information from 77 patients in a randomized, controlled diabetes intervention study in the USA showed that $34 \%$ of patients stated that paying for medications was a reason for the lack of adherence [50]. In a study in 
France, a multivariate regression analysis was used to examine factors associated with adherence, which were determined from a patient-reported questionnaire [51]. Poor adherence was significantly associated with financial difficulties as well as a number of social factors such as taking the medications alone, a need for information, and lack of family or social support.

There have been many trials of educational intervention methods involving allied health professionals, which have resulted in increased adherence where benefits outweigh the costs associated with the intervention [52, 53]. However, the effects of such interventions are inconsistent between studies and more research of methods to reduce nonadherence and validate cost effectiveness for diabetes is required [54].

\section{Patient-Provider Interaction}

Interaction between patients with diabetes and their healthcare providers has also been shown to have an impact on adherence to medication. In the French ENTRED study of adherence from a self-administered questionnaire, good adherence was significantly associated with follow-up by a diabetes specialist and a good relationship between patients and physicians [51]. A poor relationship between the patient and provider was reported significantly more frequently by patients with poor adherence to medications and glucose monitoring, and was associated with higher $\mathrm{HbA}_{1 \mathrm{c}}$ levels [55].

In the multinational DAWN study, the patient relationship with the healthcare provider and having a diabetes nurse at the premises were positively correlated with adherence to both medication and lifestyle regimens [56]. It was suggested that communication between patients and healthcare providers resolved patient distress, and patients were more informed about treatment options and decisions, which improved adherence and glycemic control.

\section{OUTCOMES OF POOR ADHERENCE}

\section{Clinical Consequences}

The main consequence of poor adherence to medications for glycemic control is decreased glycemic control, leading to the known complications of diabetes, including microvascular and macrovascular diseases and altered lipid metabolism [5]. For example, in a retrospective cohort study of 11,532 patients in which medication adherence was calculated as the proportion of days covered for filled prescriptions of OHAs, antihypertensives and statins, multivariate analyses showed that medication nonadherence was associated with higher $\mathrm{HbA}_{1 \mathrm{c}}$, blood pressure, and LDL cholesterol levels [57]. Such changes lead to an increased risk of morbidity and mortality [17]. In the above cohort study, the increased risks for allcause hospitalization (odds ratio [OR] 1.58; 95\% CI 1.38-1.81; $P<0.001)$ and all-cause mortality (OR 1.81; 95\% CI 1.46-2.23; $P<0.001$ ) were significant (Table 2) [57]. In a study of 15,984 patients with insulin-treated type 2 diabetes in the UK, medication noncompliance, as assessed by the attending physician or nurse over a 30-month period of observation, was an independent risk factor for all-cause mortality (hazard ratio after adjustment for confounding factors 1.58; 95\% CI 1.17-2.14) [58].

\section{Economic Impact}

The health-related costs associated with type 2 diabetes morbidity and mortality are continually increasing and are exacerbated by 
Table 2 Association between medication nonadherence and outcomes; adapted with permission from Ho et al. [57]

\begin{tabular}{lllll}
\hline & No. of patients & $\begin{array}{l}\text { Nonadherent } \\
\text { patients, (\%) }\end{array}$ & & \multicolumn{2}{l}{$\begin{array}{l}\text { Odds ratio (95\% confidence interval) } \\
\text { All-cause } \\
\text { mortality }^{\mathbf{a}}\end{array}$} & $\begin{array}{l}\text { All-cause } \\
\text { hospitalization }^{\mathbf{a}}\end{array}$ \\
\hline All therapy & 11,532 & 21.3 & $1.81(1.46-2.23)$ & $1.58(1.38-1.81)$ \\
Oral antihyperglycemics & 7,883 & 20.3 & $1.39(1.07-1.82)$ & $1.38(1.21-1.58)$ \\
Antihypertensives & 6,217 & 19.1 & $1.58(1.22-2.05)$ & $1.44(1.24-1.67)$ \\
Statins & 6,486 & 24.8 & $2.07(1.54-2.80)$ & $1.39(1.18-1.63)$ \\
\hline
\end{tabular}

${ }^{a}$ Unselected multivariable models were constructed to maximally adjust for confounding, and included sex, age, comorbidities, medication, blood pressure, low density lipoprotein cholesterol and $\mathrm{HbA}_{1 \mathrm{c}}$; odds ratios and $95 \%$ confidence intervals were calculated for each independent variable in the multivariable models

resultant long-term complications. It was estimated in the USA in 2007 that the direct and indirect cost of diabetes was $\$ 218$ billion per year [59]. The median annual costs for individuals with diet-controlled type 2 diabetes who had no other complications were estimated to be $\$ 1,700$ for men and $\$ 2,100$ for women [60]. Estimates for Spain in 2002 indicated that the direct healthcare costs for diabetic patients were $€ 2.4$ to $€ 2.7$ billion, which corresponded to between $6.3 \%$ and $7.4 \%$ of the total national healthcare system expenditure [61]. Hospital costs contributed most to the expenditure (€933 million), followed by non-insulin and nonantihyperglycemic drugs (€777 to €932 million). The costs of insulin and OHAs were much lower (€311 million), as were primary care visits ( $€ 181$ to $€ 272$ million), specialized visits ( $€ 127$ to $€ 145$ million), and disposable elements ( $€ 70$ to $€ 81$ million) [61].

There have been a number of analyses of the effect of adherence on costs and, in an analysis of seven studies, an inverse correlation between hospitalization costs and adherence was shown [16]. In a retrospective study of more than 100,000 patients with type 2 diabetes in which mean adherence to one or more OHAs ranged from $61.3 \%$ to $73.8 \%$ during 2 years of follow- up, annual all-cause healthcare costs were increased by $\$ 336$ for nonadherent metformin users and by $\$ 1,509$ for nonadherent sulfonylurea users, compared with adherent patients [62]. The authors concluded that a return on investment was possible by increasing the adherence to antidiabetic therapies.

Using propensity score methods to assess the effect of adherence on costs, the rate of hospitalization decreased from $15 \%$ to $11.5 \%$ when antidiabetic drug adherence was increased from $50 \%$ to $100 \%$ [63]. Increased adherence resulted in a mean increase in antidiabetic drug spending of $\$ 776$ per patient per year; however, the cost saving for averted hospitalizations was $\$ 886$ per patient per year, providing a cost offset of $\$ 1.14$ per $\$ 1.00$ spent.

\section{IMPROVING ADHERENCE}

In 2003, the WHO emphasized that "increasing the effectiveness of adherence interventions may have a far greater impact on the health of the population than any improvement in specific medical treatments" [7]. Until now, interventions aimed at improving medication adherence have only been partially successful, which may in part be due to the multifactorial 
nature of adherence. In addition to reducing medication complexity, factors such as better patient information, education and motivation have been shown in a recent study in Spain to be associated with improved adherence [64]. Factors that affect adherence and that are associated with improvement are summarized in Table 3.

\section{Perceived Improvement}

It is probable that patients who achieve glycemic control with fewer adverse events, such as weight gain and hypoglycemia, are more likely to remain adherent to medications. A number of currently available antidiabetic medications are effective in lowering glucose but some, including insulin, sulfonylureas and thiazolidinediones, are associated with weight gain and/or hypoglycemia. Some newer medications, such as dipeptidyl peptidase-4 (DPP-4) inhibitors and glucagon-like peptide-1 (GLP-1) receptor agonists, have improved records in relation to these side effects. The observed reduction in weight gain shown by GLP-1 receptor agonists potentially reduces adverse cardiovascular outcomes and could contribute to better adherence $[65,66]$.

\section{Reducing Complexity}

Once a regimen of glucose-lowering medications has been established, patients are largely responsible for day-to-day management of their glycemic control. This normally involves a daily routine that many patients have difficulties in following [67, 68]. Modifications might involve decreasing the number of therapies and frequency of therapy, and altering the route of administration, although this is not always straightforward. A reduction in non-fatal myocardial infarction and events associated with coronary heart disease can be achieved with intensive glucose-lowering treatment, but involves more medications than conventional treatment [30]. A meta-regression analysis also indicated that intensive treatment for glycemic and cardiovascular control significantly reduces the risk of diabetes-related complications [39], although such treatment may require three to ten tablets per day [69]. In the ACCORD trial, an intensive glucose-lowering treatment was related to a higher frequency of both minor and major hypoglycemia compared with conventional therapy. It was not clear whether

Table 3 Factors that have been shown to reduce adherence and factors associated with improvement in adherence to medications taken by patients with type 2 diabetes

\begin{tabular}{ll}
\hline Factors associated with reduced adherence & Factors associated with improved adherence \\
\hline $\begin{array}{l}\text { Polypharmacy, complexity of medication regimens } \\
\text { and injectable medications }\end{array}$ & $\begin{array}{c}\text { Reduced treatment complexity, fixed-dose combinations and } \\
\text { decreased frequency of administration }\end{array}$ \\
$\begin{array}{l}\text { Associated adverse events, including weight gain } \\
\text { cardiovascular problems and hypoglycemia }\end{array}$ & $\begin{array}{c}\text { Medications that are weight-neutral or weight reducing, and with } \\
\text { glucose-dependent effects, leading to decreased hypoglycemia }\end{array}$ \\
$\begin{array}{l}\text { Perceptions of efficacy and safety (both patients } \\
\text { and healthcare providers) }\end{array}$ & $\begin{array}{l}\text { Education and increased knowledge } \\
\text { Economic considerations }\end{array}$ \\
$\begin{array}{l}\text { Patient-healthcare provider relationship } \\
\text { Ensure benefits outweigh costs }\end{array}$ \\
$\begin{array}{c}\text { Improved continuity of care, and increased communication } \\
\text { through websites and electronic records }\end{array}$
\end{tabular}


the hypoglycemia had an impact on the increased mortality observed in the intensively treated group [18].

There is considerable evidence of decreased adherence related to polytherapy and multiple daily-dosing schedules in various medical disorders. For example, an analysis of 76 studies of electronic monitoring showed that the mean dose-taking compliance declined significantly $(P<0.001)$ as the number of daily doses increased (Fig. 2) [70]. Currently, there are a number of fixed-dose combinations of agents for the treatment of hyperglycemia in type 2 diabetes, which simplify administration regimens and increase patient adherence compared with equivalent combinations of separate tablets [71].

In a database analysis of 17 studies carried out between 1998 and 2009, adherence was reported in 7 studies and was 10-13\% higher for single-tablet, fixed-dose formulations than loose-dose regimens in patients with type 2 diabetes starting combination therapy [72]. Only one study in that analysis showed no

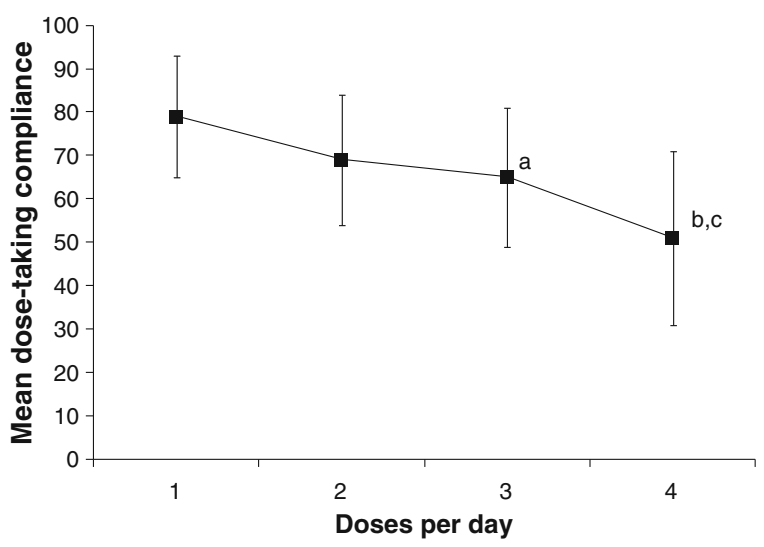

Fig. 2 Dose-taking compliance by frequency of administration per day, using pooled data from published reports included in Claxton et al. [70]. 'Once daily versus threetimes daily, $P=0.008$. ${ }^{\mathrm{b}}$ Once daily versus four-times daily, $P<0.001$. 'Twice daily versus four-times daily, $P<0.001$. Points show mean and standard deviation adherence advantage for combination therapy. The decrease in adherence was greater in patients who switched from monotherapy to loose-dose combination therapy (10\%) than in those who switched to fixed-tablet combination therapy $(1.5 \%, \quad P<0.001)$. Patients on fixed-dose combinations used fewer healthcare resources, and had decreased healthcare costs and increased life expectancy compared with those on loose-dose combinations [72]. Similar results were obtained in a review of 11 retrospective studies where there was a $16 \%$ improvement in adherence in patients converting from polytherapy to a single combination tablet [24], and a $12.4 \%$ improvement in adherence was reported in another study of 22,332 patients receiving either fixed-dose combination therapy or dual therapy [73]. The increased adherence using fixed-dose combinations is associated with improved outcomes. A meta-analysis of studies of therapies for type 2 diabetes showed that fixed-dose combinations resulted in a significantly greater decrease in $\mathrm{HbA}_{1 \mathrm{c}}$ than the equivalent co-administered dual therapies (pooled mean difference $-0.53 \%, P<0.001$ ), and there was an associated increase in adherence, determined by MPR, with the fixed-dose combination therapy [74]. Data from a physician-interview study indicated that the decision to prescribe a fixed-dose combination was associated with improved treatment satisfaction among patients [75]. Physicians were less likely to prescribe a fixeddose combination as the $\mathrm{HbA}_{1 \mathrm{c}}$ level increased. However, $\mathrm{HbA}_{1 \mathrm{c}}$ was $0.25 \%$ lower for patients on a fixed-dose combination versus an equivalent free-form combination, and $\mathrm{HbA}_{1 \mathrm{c}}$ was $0.42 \%$ lower for patients perceived by the physician as 'fairly compliant' compared with 
patients perceived by the physician as 'poorly' or 'not at all compliant'; these two factors were additive, with no interaction, and the authors suggested that giving a fixed-dose combination to poorly compliant patients could improve both compliance and $\mathrm{HbA}_{1 \mathrm{c}}$ level [75].

In patients with type 2 diabetes, the number of doses required per day has also been shown to influence adherence. In a review of a pharmacy claims database, patients on oncedaily regimens had higher adherence (61\%) than those on twice-daily regimens (52\%) [76]. A prospective assessment of 11,896 patients with type 2 diabetes treated with either one or two OHAs showed that $\mathrm{HbA}_{1 \mathrm{c}}$ level was positively correlated with daily-dosing frequency of these agents [25]. Another study of 4,802 patients found that reducing multipleadministration treatments from $69.5 \%$ to $56.8 \%$ of the patients and increasing once-daily dosing from $12 \%$ to $58.4 \%$ led to an increase from $44 \%$ to $69.5 \%$ of patients achieving optimal compliance with therapy after 6 months [77].

Adherence to injectable regimens is lower than to oral drugs and many patients with diabetes are reluctant to start injections, despite the importance of glycemic control. Some of the barriers to injectable medications can be overcome by education and counseling, but resistance and clinical inertia remain a problem associated with the lifelong nature of the disease [47, 48]. There have been many improvements in insulin therapy over the years that have increased adherence, such as the use of pen-like devices compared with conventional syringe and needles. Other improvements have included the nature of the insulin preparation. For example, in a study of modern premixed insulins administered three times per day to 115 outpatients with type 2 diabetes, mean $\mathrm{HbA}_{1 \mathrm{c}}$ levels, fasting blood glucose, serum triglycerides and the frequency of minor hypoglycemic episodes all decreased, and weight was unchanged, after 2.9 years [78]. The number of non-compliant patients decreased significantly from $34 \%$ to $22 \%$ $(P=0.001)$ during premixed insulin treatment versus previous administration of OHA and/or basal, prandial or separate basal-bolus insulins.

Similar outcomes have been observed in studies of other chronic diseases. In a general review of 20 studies published between 1986 and 2007, significantly higher adherence rates were seen in patients using less frequently dosed medications $(P<0.05)$ in 15 of the 20 studies [79]. It is of interest that weekly compared with daily dosing also increased adherence. In an analysis of 11 trials, adherence was $8.8-12 \%$ higher for once-weekly dosing than for oncedaily dosing [80]. In the treatment of major depressive disorder, patient compliance was better with once-weekly (85.9\%) compared with daily (79.4\%) fluoxetine treatment [81], and similar observations were made with bisphosphonate treatment for osteoporosis [82]. Nevertheless, when adherence was poor not all studies demonstrated improvements with less frequent dosing [52]. Although the frequency of dosing appeared to have a significant impact on adherence in most cases, efficacy and safety also remained an important determinant of patient preference [83].

In a survey of 1,516 patients with type 2 diabetes, $46.8 \%$ reported that they would prefer a once-weekly injectable medication rather than a daily regimen; current injection users were more than twice as likely to agree as non-injection users (73.1\% versus $31.5 \%$; $P<0.001)$ [84].

\section{Education and Intervention}

A literature review of studies of older patients with type 2 diabetes or cardiovascular disease 
found an inconsistent relationship between adherence and health literacy, defined as a patient's ability to understand the information needed to appropriately manage their disease [85]. The authors concluded that measures to improve health literacy may not necessarily increase medication adherence. However, diabetes self-management education is regarded as essential for patients with type 2 diabetes [5, 18]. When adherence education was added to pharmacotherapy for 172 patients with uncontrolled diabetes, mean fasting blood glucose and $\mathrm{HbA}_{1 \mathrm{c}}$ values of patients in the intervention group decreased significantly compared with those in the control group $(P<0.001)$ after 3 months [86]. However, data from a comprehensive literature review suggested that such interventions did not improve adherence if it was already high [52].

Improving continuity of care (COC) for patients with type 2 diabetes through better patient-physician relationships and greater information sharing has also been shown to be associated with increased adherence and improved outcomes [87]. For patients with a high versus a low score for COC, the OR for adherence (defined from MPR $\geq 80 \%$ ) was 3.37 (95\% CI 3.15-3.60). In a study of elderly patients, the OR for receiving inappropriate drugs was 0.44 (95\% CI 0.43-0.45) for patients with the highest versus the lowest COC, and the OR for duplicated medication was 0.22 (95\% CI $0.22-0.23)$ [88]. There was also a reduction in likelihood of hospitalization, and the results indicated that improved COC was associated with a significant decrease in overall healthcare expenditure.

In a randomized trial where patients received up to 10 telephone calls from their health educator at 4 - to 6-week intervals over 1 year, there was a significant improvement in medication adherence for the patients who were on OHAs. However, this intervention was not effective in those patients taking insulin [89]. Newer methods to increase communication and relationships between patients and healthcare providers are being developed using resources such as electronic medical records [90] and websites [91], and it is anticipated that these will result in improved medication adherence.

\section{Co-payment and Adherence}

For patients with diabetes, the average annual costs per patient were shown in a study in Italy to be lower for fixed-dose combination therapies than either monotherapy or dual therapies [92]. Similar to other therapeutic areas, the cost of medications for diabetes increases continually. One method of slowing the rise in healthcare costs is to increase the levels of co-payment by patients. A study in Australia showed that when co-payments under the pharmaceutical benefits scheme increased by $24 \%$ in 2005, there was a significant decrease in dispensing volumes of various medications, including those for diabetes and cardiovascular disease [93]. A United States study of levels of co-payment for OHAs [94] showed a persistent reduction in previously established OHA use when the increased cost sharing was more than $\$ 10$ per 30-day supply. Another United States study demonstrated that a cost-sharing increase of $\$ 10$ was associated with a $5.4 \%$ decrease in adherence to OHAs; the decreased adherence was associated with an increase in diabetesrelated complications and resultant costs [95]. Conversely, a reduction in co-payment from $\$ 15.3$ to $\$ 10.1$ for diabetes medications was associated with increased adherence, from $75.3 \%$ to $82.6 \%$ [96]. 
Financial incentives have been suggested as a means of increasing compliance with medications, although they are not applicable to all patients [97]. Reducing copayments for statins in Medicare beneficiary patients with diabetes was associated with increased adherence and reduced medical costs, particularly in high-risk cases [98]. Limiting the payments that patients are required to make may increase adherence and could reduce the overall long-term costs.

\section{CONCLUSION}

It is evident from many studies that type 2 diabetes is a progressive disease and pharmacologic treatment is essential to maintain glycemic control and reduce adverse cardiovascular outcomes. Even though adherence to medications leads to beneficial outcomes, it is often poor. There are numerous reasons for poor adherence including age, social and psychological factors, education and a lack of understanding of the long-term benefits of treatment, the complexity of the medication regimen, cost of medication and negative treatment perceptions. Poor communication between doctor and patient, adverse outcomes such as weight gain and hypoglycemia, and failure of clinicians to modify medications appropriately can also affect adherence. New innovative methods are needed to assist those patients who fail in their medication compliance [54]. Measures to increase patient satisfaction and counteract a lack of adherence must be multifactorial; strategies should include a reduction in the complexity of the prescription regimen, educational initiatives, improved doctorpatient communication, reminder systems and reduced costs.

\section{BULLET-POINT SUMMARY}

- Adherence to therapy is defined as the extent to which a person's behavior in taking medication, following a diet, and/or executing lifestyle changes, corresponds with agreed recommendations from a healthcare provider.

- Patients presenting with type 2 diabetes mellitus are initially encouraged to maintain a healthy diet and exercise regimen, followed by early medication that generally includes one or more oral antidiabetic drugs and later may include an injectable treatment.

- Recommended glycemic goals are achieved by less than $50 \%$ of patients, which may be associated with reduced adherence to therapies, and may lead to complications of diabetes over time.

- Adherence to long-term exercise programs can vary between $10 \%$ and $80 \%$. Data from different studies show that adherence to oral hypoglycemic agents (OHA) ranged from $36 \%$ to $93 \%$ in patients remaining on treatment for 6-24 months. In retrospective insulin studies, adherence was $62 \%$ and $64 \%$ for long-term and new-start insulin users, respectively.

- Reasons for nonadherence to therapies include age, information, perception and duration of disease, complexity of dosing regimen, polytherapy, psychological factors, safety, tolerability and cost.

- Measures to increase therapy adherence in type 2 diabetes include reducing complexity by fixed-dose combinations and less frequent dosing requirements, using medications with improved safety profile, educational initiatives, improved patienthealthcare provider communication and social support, which may help to reduce costs. 


\section{ACKNOWLEDGMENTS}

The authors would like to thank Dr Peter Bates, Cambridge Medical Writing Services, UK for editorial assistance in the preparation of the manuscript, funded by Eli Lilly and Company. The article processing charges for this article were funded by Eli Lilly and Company. The authors meet the criteria for authorship as recommended by the International Committee for Medical Journal Editors (ICMJE), were responsible for all content and editorial decisions, and were involved in all stages of the manuscript preparation. Dr. Garcia-Pérez is the guarantor of this article and takes responsibility for the integrity of the work as a whole.

Conflict of interest. L.E. Garcia-Pérez, M. Álvarez and T. Dilla are employees of Eli Lilly and Company, Spain. V. Gil-Guillén and D. Orozco-Beltrán report no conflict of interest.

Open Access. This article is distributed under the terms of the Creative Commons Attribution Noncommercial License which permits any noncommercial use, distribution, and reproduction in any medium, provided the original author(s) and the source are credited.

\section{REFERENCES}

1. Cheung BM, Ong KL, Cherny SS, Sham PC, Tso AW, Lam KS. Diabetes prevalence and therapeutic target achievement in the United States, 1999 to 2006. Am J Med. 2009;122:443-53.

2. International Diabetes Federation. Diabetes and impaired glucose tolerance. IDF Diabetes Atlas, 5th ed. Brussels, Belgium: International Diabetes Federation, 2012.

3. King DE, Mainous AG, Carnemolla M, Everett CJ. Adherence to healthy lifestyle habits in US adults, 1988-2006. Am J Med. 2009;122:528-34.
4. Vivian EM. Type 2 diabetes in children and adolescents-the next epidemic? Curr Med Res Opin. 2006;22:297-306.

5. American Diabetes Association. Standards of medical care in diabetes: 2013. Diabetes Care. 2013;36(Suppl 1):S11-66.

6. Grant RW, Pirraglia PA, Meigs JB, Singer DE. Trends in complexity of diabetes care in the United States from 1991 to 2000. Arch Intern Med. 2004;164:1134-9.

7. World Health Organization: Adherence to longterm therapies. Evidence for action. Geneva: World Health Organization; 2003.

8. Osterberg L, Blaschke T. Adherence to medication. N Engl J Med. 2005;353:487-97.

9. Cramer JA, Roy A, Burrell A, et al. Medication compliance and persistence: terminology and definitions. Value Health. 2008;11:44-7.

10. Guillausseau P-J. Impact of compliance with oral antihyperglycemic agents on health outcomes in type 2 diabetes mellitus: a focus on frequency of administration. Treat Endocrinol. 2005;4: 167-75.

11. Ho PM, Bryson CL, Rumsfeld JS. Medication adherence: its importance in cardiovascular outcomes. Circulation. 2009;119:3028-35.

12. Caro JJ, Ishak KJ, Huybrechts KF, Raggio G, Naujoks C. The impact of compliance with osteoporosis therapy on fracture rates in actual practice. Osteoporos Int. 2004;15:1003-8.

13. Donnan PT, MacDonald TM, Morris AD. Adherence to prescribed oral hypoglycaemic medication in a population of patients with type 2 diabetes: a retrospective cohort study. Diabet Med. 2002;19:279-84.

14. Karter AJ, Parker MM, Moffet HH, Ahmed AT, Schmittdiel JA, Selby JV. New prescription medication gaps: a comprehensive measure of adherence to new prescriptions. Health Serv Res. 2009;44:1640-61.

15. Steiner JF, Prochazka AV. The assessment of refill compliance using pharmacy records: methods, validity, and applications. J Clin Epidemiol. 1997;50:105-16.

16. Breitscheidel L, Stamenitis S, Dippel FW, Schöffski O. Economic impact of compliance to treatment with antidiabetes medication in type 2 diabetes mellitus: a review paper. J Med Econ. 2010;13:8-15. 
17. Bailey CJ, Kodack M. Patient adherence to medication requirements for therapy of type 2 diabetes. Int J Clin Pract. 2011;65:314-22.

18. Inzucchi $\mathrm{SE}$, Bergenstal $\mathrm{RM}$, Buse $\mathrm{JB}$, et al. Management of hyperglycaemia in type 2 diabetes: a patient-centered approach. Position statement of the American Diabetes Association (ADA) and the European Association for the Study of Diabetes (EASD). Diabetologia. 2012;55: 1577-96.

19. Praet SF, van Loon LJ. Exercise therapy in type 2 diabetes. Acta Diabetol. 2009;46:263-78.

20. Praet SF, van Rooij ES, Wijtvliet A, et al. Brisk walking compared with an individualised medical fitness programme for patients with type 2 diabetes: a randomised controlled trial. Diabetologia. 2008;51:736-46.

21. Dunstan DW, Vulikh E, Owen N, Jolley D, Shaw J, Zimmet P. Community center-based resistance training for the maintenance of glycemic control in adults with type 2 diabetes. Diabetes Care. 2006;29:2586-91.

22. Schultz JA, Sprague MA, Branen LJ, Lambeth S. A comparison of views of individuals with type 2 diabetes mellitus and diabetes educators about barriers to diet and exercise. J Health Commun. 2001;6:99-115.

23. Rozenfeld Y, Hunt JS, Plauschinat C, Wong KS. Oral antidiabetic medication adherence and glycemic control in managed care. Am J Manag Care. $2008 ; 14: 71-5$.

24. Cramer JA. A systematic review of adherence with medications for diabetes. Diabetes Care. 2004;27:1218-24.

25. Guillausseau P-J. Influence of oral antidiabetic drugs compliance on metabolic control in type 2 diabetes: a survey in general practice. Diabetes Metab. 2003;29:79-81.

26. Trinacty CM, Adams AS, Soumerai SB, et al. Racial differences in long-term adherence to oral antidiabetic drug therapy: a longitudinal cohort study. BMC Health Serv Res. 2009;9:24.

27. Karter AJ, Subramanian U, Saha C, et al. Barriers to insulin initiation: the translating research into action for diabetes insulin starts project. Diabetes Care. 2010;33:733-5.

28. Donnelly LA, Morris AD, Evans JM; DARTS/MEMO collaboration. Adherence to insulin and its association with glycaemic control in patients with type 2 diabetes. QJM. 2007;100:345-50.
29. Yurgin NR, Boye KS, Dilla T, Suriñach NL, Llach XB. Physician and patient management of type 2 diabetes and factors related to glycemic control in Spain. Patient Prefer Adherence. 2008;2:87-95.

30. Ray KK, Seshasai SR, Wijesuriya S, et al. Effect of intensive control of glucose on cardiovascular outcomes and death in patients with diabetes mellitus: a meta-analysis of randomised controlled trials. Lancet. 2009;373:1765-72.

31. Bramley TJ, Gerbino PP, Nightengale BS, FrechTamas F. Relationship of blood pressure control to adherence with antihypertensive monotherapy in 13 managed care organizations. J Manag Care Pharm. 2006;12:239-45.

32. Donnelly LA, Doney AS, Morris AD, Palmer CN, Donnan PT. Long-term adherence to statin treatment in diabetes. Diabet Med. 2008;25:850-5.

33. Gaede P, Vedel P, Larsen N, Jensen GV, Parving HH, Pedersen O. Multifactorial intervention and cardiovascular disease in patients with type 2 diabetes. N Engl J Med. 2003;348:383-93.

34. Mateo JF, Gil-Guillén VF, Mateo E, Orozco D, Carbayo JA, Merino J. Multifactorial approach and adherence to prescribed oral medications in patients with type 2 diabetes. Int J Clin Pract. 2006;60:422-8.

35. Curtis JR, Xi J, Westfall AO, et al. Improving the prediction of medication compliance: the example of bisphosphonates for osteoporosis. Med Care. 2009;47:334-41.

36. Thayer S, Arondekar B, Harley C, Darkow TE. Adherence to a fixed-dose combination of rosiglitazone/glimepiride in subjects switching from monotherapy or dual therapy with a thiazolidinedione and/or a sulfonylurea. Ann Pharmacother. 2010;44:791-9.

37. Cooke CE, Lee HY, Tong YP, Haines ST. Persistence with injectable antidiabetic agents in members with type 2 diabetes in a commercial managed care organization. Curr Med Res Opin. 2010;26:231-8.

38. Dilla T, Costi M, Boye KS, et al. The impact of obesity in the management and evolution of diabetes mellitus. Rev Clin Esp. 2008;208:437-43.

39. Mannucci E, Monami M, Lamanna C, Gori F, Marchionni N. Prevention of cardiovascular disease through glycemic control in type 2 diabetes: a meta-analysis of randomized clinical trials. Nutr Metab Cardiovasc Dis. 2009;19:604-12.

40. Terry T, Raravikar K, Chokrungvaranon N, Reaven PD. Does aggressive glycemic control benefit 
macrovascular and microvascular disease in type 2 diabetes? Insights from ACCORD, ADVANCE, and VADT. Curr Cardiol Rep. 2012;14:79-88.

41. Skyler JS, Bergenstal R, Bonow RO, et al. Intensive glycemic control and the prevention of cardiovascular events: implications of the ACCORD, ADVANCE, and VA diabetes trials. Circulation. 2009;119:351-7.

42. Hauber AB, Mohamed AF, Johnson FR, Falvey H. Treatment preferences and medication adherence of people with Type 2 diabetes using oral glucoselowering agents. Diabet Med. 2009;26:416-24.

43. Donnelly LA, Morris AD, Pearson ER. Adherence in patients transferred from immediate release metformin to a sustained release formulation: a population-based study. Diabetes Obes Metab. 2009;11:338-42.

44. Pollack MF, Purayidathil FW, Bolge SC, Williams SA. Patient-reported tolerability issues with oral antidiabetic agents: associations with adherence; treatment satisfaction and health-related quality of life. Diabetes Res Clin Prac. 2010;87:204-10.

45. Broadbent E, Donkin L, Stroh JC. Illness and treatment perceptions are associated with adherence to medications, diet, and exercise in diabetic patients. Diabetes Care. 2011;34:338-40.

46. Farmer A, Kinmonth AL, Sutton S. Measuring beliefs about taking hypoglycaemic medication among people with type 2 diabetes. Diabet Med. 2006;23:265-70.

47. Peyrot M, Rubin RR, Khunti K. Addressing barriers to initiation of insulin in patients with type 2 diabetes. Primary Care Diabetes. 2010;4(Suppl 1):S11-8.

48. Woudenberg YJ, Lucas C, Latour C. Scholte op Reimer WJ. Acceptance of insulin therapy: a long shot? Psychological insulin resistance in primary care. Diabet Med. 2012;29:796-802.

49. Larkin ME, Capasso VA, Chen CL, et al. Measuring psychological insulin resistance: barriers to insulin use. Diabetes Educ. 2008;34:511-7.

50. Odegard PS, Gray SL. Barriers to medication adherence in poorly controlled diabetes mellitus. Diabetes Educ. 2008;34:692-7.

51. Tiv M, Viel J-F, Mauny F, et al. Medication adherence in type 2 diabetes: the ENTRED study 2007, a French population-based study. PLoS ONE. 2012;7:e32412.

52. Doggrell SA. Does intervention by an allied health professional discussing adherence to medicines improve this adherence in type 2 diabetes? Diabet Med. 2010;27:1341-9.

53. Boren SA, Fitzner KA, Panhalkar PS, Specker JE. Costs and benefits associated with diabetes education: a review of the literature. Diabetes Educ. 2009;35:72-96.

54. Haynes RB, Ackloo E, Sahota N, McDonald HP, Yao $X$. Interventions for enhancing medication adherence. Cochrane Database Syst Rev. 2008;(2):CD000011.

55. Ciechanowski PS, Katon WJ, Russo JE, Walker EA. The patient-provider relationship: attachment theory and adherence to treatment in diabetes. Am J Psychiatry. 2001;158:29-35.

56. Rubin RR, Peyrot M, Simnerio LM. Health care and patient-reported outcomes: results of the crossnational Diabetes Attitudes, Wishes and Needs (DAWN) study. Diabetes Care. 2006;29:1149-55.

57. Ho PM, Rumsfeld JS, Masoudi FA, et al. Effect of medication nonadherence on hospitalization and mortality among patients with diabetes mellitus. Arch Intern Med. 2006;166:1836-41.

58. Currie CJ, Peyrot M, Morgan CL, et al. The impact of treatment noncompliance on mortality in people with type 2 diabetes. Diabetes Care. 2012;35: 1279-84.

59. Dall T, Zhang Y, Chen Y, Quick WW, Yang WG, Fogli J. The economic burden of diabetes. Health Aff. 2010;29:297-303.

60. Brandle M, Zhou H, Smith BR, et al. The direct medical cost of type 2 diabetes. Diabetes Care. 2003;26:2300-4.

61. Oliva J, Lobo F, Molina B, Monereo S. Direct health care costs of diabetic patients in Spain. Diabetes Care. 2004;27:2616-21.

62. Hansen RA, Farley JF, Droege M, Maciejewski ML. A retrospective cohort study of economic outcomes and adherence to monotherapy with metformin, pioglitazone, or a sulfonylurea among patients with type 2 diabetes mellitus in the United States from 2003 to 2005. Clin Ther. 2010;32:1308-19.

63. Encinosa WE, Bernard D, Dor A. Does prescription drug adherence reduce hospitalizations and costs? The case of diabetes. Adv Health Econ Health Serv Res. 2010;22:151-73.

64. Carratalá-Munuera MC, Gil-Guillen VF, OrozcoBeltrán D, et al. Barriers associated with poor control in Spanish diabetic patients. A consensus study. Int J Clin Pract 2013. doi:10.1111/ijcp. 12160. 
65. Buysschaert M, Preumont V, Oriot PR, et al. Oneyear metabolic outcomes in patients with type 2 diabetes treated with exenatide in routine practice. Diabetes Metab. 2010;36:381-8.

66. Drucker DJ, Sherman SI, Gorelick FS, Bergenstal RM, Sherwin RS, Buse JB. Incretin-based therapies for the treatment of type 2 diabetes: evaluation of the risks and benefits. Diabetes Care. 2010; $33: 428-33$

67. Ho PM, Magid DJ, Masoudi FA, McClure DL, Rumsfeld JS. Adherence to cardioprotective medications and mortality among patients with diabetes and ischemic heart disease. BMC Cardiovasc Disord. 2006;6:48.

68. Lau DT, Nau DP. Oral antihyperglycemic medication nonadherence and subsequent hospitalization among individuals with type 2 diabetes. Diabetes Care. 2004;27:2149-53.

69. Miccoli R, Penno G, Del Prato S. Multidrug treatment of type 2 diabetes: a challenge for compliance. Diabetes Care. 2011;34(Suppl 2): S231-5.

70. Claxton AJ, Cramer J, Pierce C. A systematic review of the associations between dose regimens and medication compliance. Clin Ther. 2001;23: 1296-310.

71. Bailey CJ, Day C. Fixed-dose single tablet antidiabetic combinations. Diabetes Obes Metab. 2009;11:527-33.

72. Hutchins V, Zhang B, Fleurence RL, Krishnarajah G, Graham J. A systematic review of adherence, treatment satisfaction and costs, in fixed-dose combination regimens in type 2 diabetes. Curr Med Res Opin. 2011;27:1157-68.

73. Cheong C, Barner JC, Lawson KA, Johnsrud MT. Patient adherence and reimbursement amount for antidiabetic fixed-dose combination products compared with dual therapy among Texas Medicaid recipients. Clin Ther. 2008;30: 1893-907.

74. Han S, Iglay K, Davies MJ, Zhang Q, Radican L. Glycemic effectiveness and medication adherence with fixed-dose combination or coadministered dual therapy of antihyperglycemic regimens: a meta-analysis. Curr Med Res Opin. 2012;28: 969-77.

75. Benford M, Milligan G, Pike J, Anderson P, Piercy J, Fermer S. Fixed-dose combination antidiabeteic therapy: real-world factors associated with prescribing choices and relationship with patient satisfaction and compliance. Adv Ther. 2012;29:26-40.
76. Dezii CM, Kawabata H, Tran M. Effects of once daily and twice-daily dosing on adherence with prescribed glipizide oral therapy for type 2 diabetes. South Med J. 2002;95:68-71.

77. Guillausseau PJ. Compliance and optimization of oral antidiabetic therapy: a longitudinal study. Presse Med. 2004;33:156-60.

78. Levit S, Toledano $\mathrm{Y}$, Wainstein J. Improved glycaemic control with reduced hypoglycaemic episodes and without weight gain using long-term modern premixed insulins in type 2 diabetes. Int $\mathrm{J}$ Clin Pract. 2011;65:165-71.

79. Saini SD, Schoenfeld P, Kaulback K, Dubinsky MC. Effect of medication dosing frequency on adherence in chronic diseases. Am J Manag Care. 2009; 15:e22-33.

80. Kruk ME, Schwalbe N. The relation between intermittent dosing and adherence: preliminary insights. Clin Ther. 2006;28:1989-95.

81. Claxton A, de Klerk E, Parry M, et al. Patient compliance to a new enteric-coated weekly formulation of fluoxetine during continuation treatment of major depressive disorder. J Clin Psychiatry. 2000;61:928-32.

82. Recker RR, Gallagher R, MacCosbe PE. Effect of dosing frequency on bisphosphonate medication adherence in a large longitudinal cohort of women. Mayo Clin Proc. 2005;80:856-61.

83. Gold DT. Understanding patient compliance and persistence with osteoporosis therapy. Drugs Aging. 2011;28:249-55.

84. Polonsky WH, Fisher L, Hessler D, Bruhn D, Best JH. Patient perspectives on once-weekly medications for diabetes. Diabetes Obes Metab. 2011;13:144-9.

85. Loke YK, Hinz I, Wang X, Salter C. Systematic review of consistency between adherence to cardiovascular or diabetes medication and health literacy in older adults. Ann Pharmacother. 2012;46:863-72.

86. Farsaei S, Sabzghabaee AM, Zargarzadeh AH, Amini M. Effect of pharmacist-led patient education on glycemic control of type 2 diabetics: a randomized controlled trial. J Res Med Sci. 2011;16:43-9.

87. Chen CC, Tseng CH, Cheng SH. Continuity of care, medication adherence, and health outcomes among patients with newly diagnosed type 2 diabetes: a longitudinal analysis. Med Care. 2013;51:231-7.

88. Chu HY, Chen CC, Cheng SH. Continuity of care, potentially inappropriate medication, and health care outcomes among the elderly: evidence from a 
longitudinal analysis in Taiwan. Med Care. 2012;50:1002-9.

89. Walker EA, Shmukler C, Ullman R, Blanco E, Scollan-Koliopoulus M, Cohen HW. Results of a successful telephonic intervention to improve diabetes control in urban adults: a randomized trial. Diabetes Care. 2011;34:2-7.

90. Morrow DG, Conner-Garcia T, Graumlich JF, et al. An EMR-based tool to support collaborative planning for medication use among adults with diabetes: design of a multi-site randomized control trial. Contemp Clin Trials. 2012;33:1023-32.

91. Lin YH, Chen RR, Guo SH, Chang HY, Chang HK. Developing a web 2.0 diabetes care support system with evaluation from care provider perspectives. J Med Syst. 2012;36:2085-95.

92. Colombo GL, Rossi E, De Rosa M, Benedetto D, Gaddi AV. Antidiabetic therapy in real practice: indicators for adherence and treatment cost. Patient Prefer Adherence. 2012;6:653-61.

93. Hynd A, Roughead EE, Preen DB, Glover J, Bulsara $\mathrm{M}$, Semmens J. The impact of co-payment increases on dispensings of government-subsidised medicines in Australia. Pharmacoepidemiol Drug Saf. 2008;17:1091-9.

94. Roblin DW, Platt R, Goodman MJ, et al. Effect of increased cost-sharing on oral hypoglycemic use in five managed care organizations: how much is too much? Med Care. 2005;43:951-9.

95. Gibson TB, Song X, Alemayehu B, Wang SS, Wadell JL, Bouchard JR, Forma F. Cost sharing, adherence, and health outcomes in patients with diabetes. Am J Manag Care. 2012;16:589-600.

96. Zeng F, An JJ, Scully R, Barrington C, Patel BV, Nichol MB. The impact of value-based benefit design on adherence to diabetes medications: a propensity score-weighted difference in difference evaluation. Value Health. 2010;13:846-52.

97. Giuffrida A, Gravelle H. Paying patients to comply: an economic analysis. Health Econ. 1998;7:569-79.

98. Davidoff A, Lopert R, Stuart B, Shaffer T, Lloyd JT, Shoemaker JS. Simulated value-based insurance design applied to statin use by Medicare beneficiaries with diabetes. Value Health. 2012; 15:404-11. 